\title{
Individual differences in protein intakes following the addition of sauce to an older persons' lunch meal, and effects at lunch are sustained over the following meal
}

Protein-specific under-nutrition is considered to affect $10-20 \%$ of UK older adults ${ }^{(1)}$, with potential detriments to health and wellbeing $^{(1,2)}$. This under-nutrition is considered to result, at least in part, from low protein intakes ${ }^{(1,3)}$. Various studies demonstrate the value of a variety of strategies based on improving food and dining experiences for increasing protein intakes ${ }^{(3,4)}$. Our studies demonstrate increased protein intakes in older adults following the addition of sauce to a lunch meal ${ }^{(5,6)}$, but while effects are largely demonstrated in the manipulated meal, benefits may be easily reduced by compensation or adjustment at subsequent (nonmanipulated) meals. This study investigated the impact of adding sauce to an older persons' lunch meal on intake at that meal and at the following meal.

Using a repeated measures design, 56 community-dwelling older adults consumed a traditional hot lunch meal with sauce and without sauce on two separate occasions, and intakes at lunch and at the following evening buffet meal were measured.

In the whole group (final $\mathrm{N}=52$ ), significantly more protein was consumed at the lunch meal with sauce compared to without sauce $(\mathrm{t}(51)=2.09, \mathrm{p}=0.04)$. Individual differences however, were also found. For some participants $(\mathrm{N}=26)$, significantly higher protein and energy intakes were found following sauce $(12.3 \mathrm{~g}$ protein, $381 \mathrm{~kJ})$, while for others $(\mathrm{N}=19)$, the addition of sauce resulted in lower protein and energy intakes $(7 \mathrm{~g}$ protein, $297 \mathrm{~kJ})$. Seven participants demonstrated no effect. Intakes at the evening meal and overall (lunch + evening meal) also followed the same pattern: those who responded to the sauce manipulation with an increase in protein intake consumed more protein and energy overall following the sauce $(11 \mathrm{~g}$ protein, $420 \mathrm{~kJ})$, while those who consumed less protein at lunch following the sauce manipulation did so again overall $(7 \mathrm{~g}$ protein, $350 \mathrm{~kJ})$. Compensation for earlier intakes was thus very poor $(0-17 \%)$ for both groups.

An absence of effects in overall intakes in these data have previously been reported ${ }^{(7)}$ having analysed the group as a whole at both lunch and evening meal. Investigating individual responses however, there are strong individual differences, and sustained effects over time. These findings suggest that the addition of sauce to an older persons' lunch meal can increase protein intakes at that meal, as has previously been demonstrated ${ }^{(5,6)}$, but that this intervention is more beneficial for some than for others. Furthermore, effects were sustained across the following meal, thus benefits that were found, were maintained. Poor compensation for earlier intakes in older adults has previously been reported ${ }^{(4)}$, but this study also extends this earlier work through consideration of protein intake during meals.

1. Cowan DT, Roberts JD, Fitzpatrick JM, While AE, Baldwin J (2004) Nurtitional status of older people in long term care settings: Current status and future directions. Int $J$ Nursing Stud 41, 225-37.

2. Wolfe RR (2012) The role of dietary protein in optimizing muscle mass, function and health outcomes in older individuals. Brit $J$ Nutr 108, S88-93.

3. Leslie WS (2011) Nutrition management in special populations: Improving the dietary intake of frail older people. Proc Nut Soc 70, 263-7.

4. Abbott RA, Whear R, Thompson-Coon J et al. (2013) Effectiveness of meal time interventions on nutritional outcomes for the elderly living in residential care. Ageing Res Rev 12,967-81.

5. Appleton KM (2009) Increases in energy, protein and fat intake following the addition of sauce to an older person's meal. Appetite 52, 161-165.

6. Best RL, Appleton KM (2011) Comparable increases in energy, protein and fat intakes following the addition of seasonings and sauces to an older person's meal. Appetite 56, 179-182.

7. Appleton KM (2015) Increased protein intakes following the addition of sauce to an older persons' lunch meal are not sustained. Proceedings of the Nutrition Society 74, E169. 